\title{
Particle physicist to become a priest
}

JoHN Polkinghorne has become a minor celebrity lately-physicist turned priest: who'd have thought of that these days? "Prof takes the cloth" headlined the Observer. The local paper had called. The church papers were full of him. But he sees no conflict. "Science and theology are not not so very different" he said.

Not that Polkinghorne is going to become a theologist. "I doubt that I could become a professional theologian; there are a lot of skills you have to acquire and I'm starting too late to do that." He wants to learn as much theology as he can and is beginning to teach himself Greek; but the job he would really like is a teaching ministry-"I enjoy trying to explain things to people".

Polkinghorne, 48 years old with 25 years in the subject, explains why be is leaving particle physics. "I've had a good run for my money for 25 years. I've played a small but useful role. But the subject is continually changing and enriching itself." (An allusion here to the new wave of interest in "field theory" in particle physics-a subject he has been involved in only obliquely).

"I admire the way my younger colleagues can move into this sort of game. Partly through time but more through a question of mental flexibility, I don't think I can make that sort of move. I could therefore tick over for a few more years, but I don't think that would be a tremendously useful use of my time. I've done most of what I can do. If I feit I was going to stick in it and make reasonably useful contributions I would probably stay with it, and regard it as being a vocation to do so."

"When you're young you like to learn new things--that's part of the fun-but if I'm honest it gets slightly wearisome as you get older, particularly in a subject like particle physics where genuinely new things do come along at quite a surprising rate."

Polkinghorne does not think the techniques he has worked with, dealing

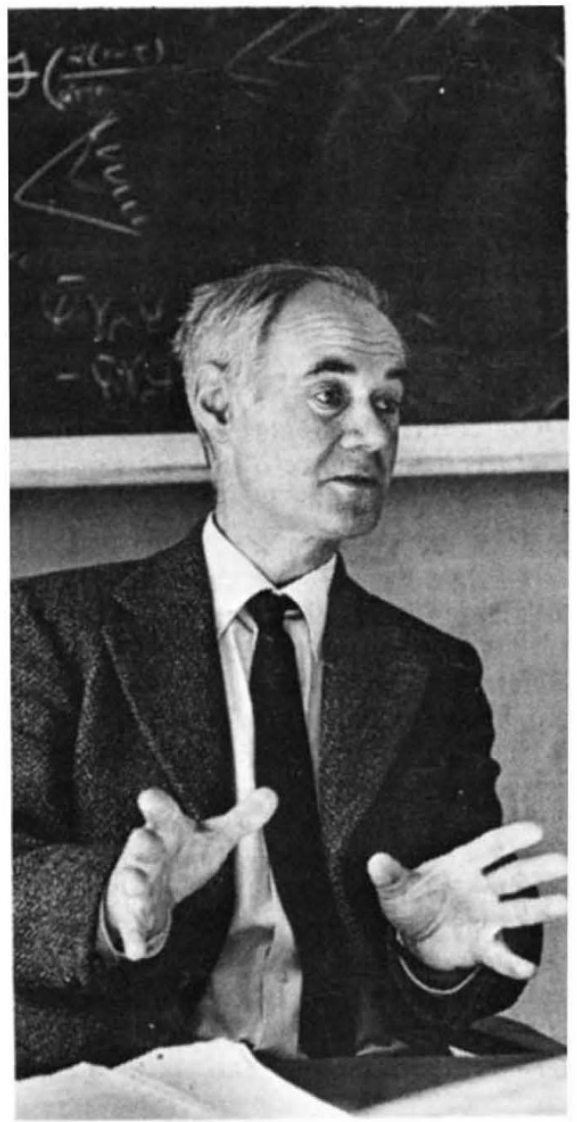

Robert Walgate talks to John Polkinghorne (above) who resigns his chair in physics at Cambridge next year

with "scattering amplitudes" directly rather than any underlying fields, are now useless--." "they will continue to be applied in different contexts". He is writing a book for graduate students to "hand on a bit of the know how" and that will be "as useful a role as I can play".

"I don't think I'm exceptional in this respect. Most people in my subject do their best work early, and they tend to do the same tricks later on. There are some subjects in which these tricks remain very important,

\section{Scientists appeal to PM over grant}

Sir Fred Hoyle and Professor Chandra Wickramasinghe, of University College, Cardiff, Wales have taken the unusual step of writing to the Prime Minister, Mr Callaghan, about the rejection of their grant application for further research on polysaccharides in interstellar space. Their grant application of last September to the Science Research Council for $£ 7,500$ to buy a minicomputer was turned down by the council's astronomy committee on the basis of insufficient merit. It seems to have been handled in the normal way by being sent out to referees, although referees' reports were not transmitted to the applicants.

$\mathrm{Mr}$ Callaghan has as yet shown no enthusiasm to intervene in what is undoubtedly a highly controversial field, leading as it does to speculations that the origin of life on Earth involved the assembly of material which exists widely in the interstellar medium. subjects whose basis is well understood, but elementary particle physics, relativistic quantum mechanics, is continually changing. There's less room for the wise old man. I think his wisdom is limited."

$\mathrm{He}$ also feels that, for good or ill, he is occupying a sensitive and important position in particle physics. A lot of talent passes through Cambridge, and whoever holds his chair has a significant influence over the way that talent turns. "That makes me more critical of what I can offer."

Altruism? "It's not entirely altruistic. I shall do less well as time goes onand that would be less satisfying to me. I need to feel that I'm doing the right job. It would be nice if, having gone up in the academic system, one could come down again. I could earn my kcep as a lecturer somewhere or other without getting hypercritical about it."

Would he recommend others to follow his course? He chuckled. "That's not for me to do. It varies so much from person to person and job to job. But it's a general phenomenon that you get less active and less in touch with the real developing point of the subject as you grow older. But there are many ways of dealing with it. Not everyone wants to become a priest!"

Polkinghorne decided two or three years ago to make a change; and he did not take long to decide that his change should be to the priesthood. "I've been a confessing Christian all my life". He resigns in October 1979, and then has a three-year teaching fellowship at Trinity College ("that will be a considerable financial help"). $\mathrm{He}$ will spend three more years in Cambridge to see his younger son through school. Two of these years he will spend at a Cambridge theological college. "I've a lot to learn." His third year he hopes to spend as a deacon, as an honorary curate in a parish near Cambridge; and then he will be a priest concentrating on the mystery of life rather than the mystery of matter.

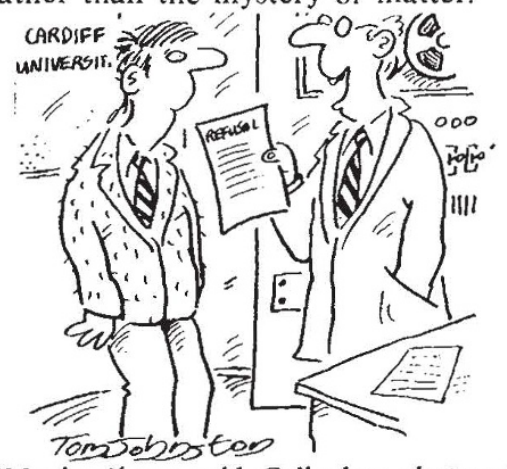

"Maybe if we told Callaghan that we're doing research into evidence of Labour voters in interstellar space. 